\title{
A Simple and Green Procedure for the Synthesis of 5-Arylidenerhodanines Catalyzed by Diammonium Hydrogen Phosphate in Water
}

\author{
Liangliang Han, Tao Wu, and Zhongqiang Zhou \\ Key Laboratory of Catalysis and Materials Science of the State Ethnic Affairs Commission and Ministry of Education, \\ College of Chemistry and Materials Science, South-Central University for Nationalities, Wuhan, Hubei 430074, China
}

Correspondence should be addressed to Zhongqiang Zhou; zhou-zq@hotmail.com

Received 13 August 2013; Accepted 10 September 2013

Academic Editors: C. Aragoncillo and N. Zohreh

Copyright (c) 2013 Liangliang Han et al. This is an open access article distributed under the Creative Commons Attribution License, which permits unrestricted use, distribution, and reproduction in any medium, provided the original work is properly cited.

\begin{abstract}
A simple and efficient procedure for the synthesis of 5-arylidenerhodanines by condensation of aromatic aldehydes with rhodanine in water using diammonium hydrogen phosphate as catalyst is described. The procedure offers several advantages including environmentally friendly, mild reaction conditions, short reaction times, high yields, and simple experimental and work-up procedures.
\end{abstract}

\section{Introduction}

Rhodanine derivatives, especially arylidenerhodanines, have shown a wide range of pharmacological activities, which include anticonvulsant, antibacterial, antiviral, and antidiabetic effects [1-3]. Arylidenerhodanines are generally prepared by reacting aldehydes and rhodanine in organic solvents and in the presence of organic bases like piperidine [2,4-8]. Recently, catalysts such as 2,2,6,6-tetramethyl piperidine $[9,10], \mathrm{NH}_{4} \mathrm{Cl} / \mathrm{NH}_{4} \mathrm{OH}[11], \mathrm{K}_{2} \mathrm{CO}_{3} /[\mathrm{bmim}] \mathrm{BF}_{4} / \mathrm{H}_{2} \mathrm{O}$ [12], $\mathrm{NaOAc/HOAc}[3,13,14]$, glycine [15], ammonium acetate [16, 17], 1-butyl-3-methyl imidazolium hydroxide [18, 19], tetrabutylammonium bromide [20], and $\mathrm{K}_{2} \mathrm{CO}_{3} / \mathrm{Al}_{2} \mathrm{O}_{3}$ [21] have been used in this reaction. Although these methods are valuable, most of them suffer from some disadvantages such as a long reaction time, low yields, the use of toxic solvent, expensive catalyst, requiring a promoter, such as microwave, and tedious work-up procedures. Thus, the development of a new procedure for the synthesis of arylidenerhodanines would be highly desirable.

Water is abundant, inexpensive, safe, and clean. Among various solvents, water is the most preferred solvent. The use of water as a solvent is the strategy commonly used toward greener chemistry. A wide range of reactions that can be conducted in or on water have been developed [22-24].
Diammonium hydrogen phosphate has been used as an efficient, nontoxic, and cheap catalyst in organic synthesis [2528]. As a part of our endeavors towards the development of efficient, and environmentally benign synthetic methodologies in water [29-32], we report herein a simple, efficient, and practical method for the synthesis of 5-arylidenerhodanines by the condensation of rhodanine with aromatic aldehydes in the presence of diammonium hydrogen phosphate in water (Scheme 1).

\section{Results and Discussion}

In order to get the best experimental reaction conditions, the reaction of rhodanine $\mathbf{1}$ and 2,4-dichlorobenzaldehyde $2 \mathbf{a}$ in the presence of $10 \mathrm{~mol} \%$ of diammonium hydrogen phosphate in water has been considered as a standard model reaction. Effects of reaction temperature on the yields of the product were studied by performing the model reaction at $80^{\circ} \mathrm{C}, 90^{\circ} \mathrm{C}$, and $100^{\circ} \mathrm{C}$, respectively (Table 1 , entries $1-3$ ). The yield of product $3 \mathbf{a}$ was increased as the reaction was raised from 80 to $90^{\circ} \mathrm{C}$. However, no increase in the yield of product $3 \mathbf{a}$ was observed as the reaction temperature was raised from 90 to $100^{\circ} \mathrm{C}$ (Table 1 , entries 2-3). Therefore, $90^{\circ} \mathrm{C}$ was chosen as the reaction temperature for all further reactions. 


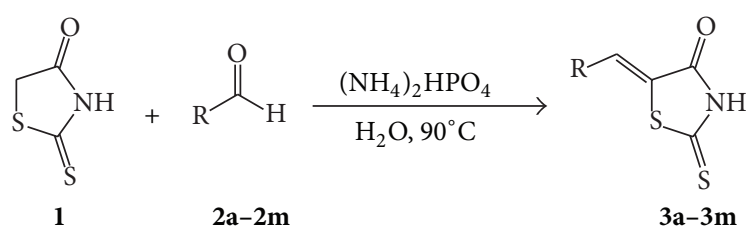

SCHEME 1: Diammonium hydrogen phosphate catalyzed synthesis of 5-arylidenerhodanines.

TABLE 1: Effect of different reaction conditions on synthesis of 5arylidenerhodanines ${ }^{\mathrm{a}}$.

\begin{tabular}{lcccc}
\hline Entry & $\begin{array}{c}\left(\mathrm{NH}_{4}\right)_{2} \mathrm{HPO}_{4} \\
(\mathrm{~mol} \%)\end{array}$ & $\begin{array}{c}\text { Temperature } \\
\left({ }^{\circ} \mathrm{C}\right)\end{array}$ & Time $(\mathrm{min})$ & Yield $(\%)^{\mathrm{b}}$ \\
\hline 1 & 10 & 80 & 45 & 85 \\
2 & 10 & 90 & 18 & 86 \\
3 & 10 & 100 & 18 & 86 \\
4 & 0 & 90 & 60 & 0 \\
5 & 5 & 90 & 18 & 75 \\
6 & 20 & 90 & 18 & 86 \\
\hline
\end{tabular}

${ }^{a}$ Reaction condition: 2,4-dichlorobenzaldehyde $(2.5 \mathrm{mmol})$, rhodanine $(2.5 \mathrm{mmol})$, and water $(3 \mathrm{~mL})$.

${ }^{\mathrm{b}}$ Isolated yield.

Moreover, we found that the yields were obviously affected by the amount of diammonium hydrogen phosphate loaded. When the amount of the catalyst decreased to $5 \mathrm{~mol} \%$ from $10 \mathrm{~mol} \%$ relative to the substrates, the yield of product 3a was reduced (Table 1, entries 2 and 5). However, the use of $20 \mathrm{~mol} \%$ of the catalyst showed the same yield and the same time was required (Table 1, entry 6). So, the use of $10 \mathrm{~mol} \%$ of catalyst is sufficient to push the reaction forward. It is noteworthy that, in the absence of a catalyst under the reaction conditions, no product formation was observed after $60 \mathrm{~min}$ (Table 1, entry 4). This result indicates that the catalyst exhibits a high catalytic activity in this transformation.

Using these optimized reaction conditions, the scope and efficiency of this approach were explored for the synthesis of a wide variety of 5-arylidenerhodanines and the obtained results are summarized in Table 2. The reaction worked well with a variety of aldehydes including those bearing an electron-withdrawing group and electron-donating group and the corresponding products were obtained with high yields in short times.

A plausible mechanism for this reaction has been suggested in Scheme 2. Ionization of diammonium hydrogen phosphate leads to the formation of hydroxide ion and ammonium ion. Subsequent reaction between the hydroxide ion and rhodanine gives rise to a rhodanine anion 5. Meanwhile, aldehyde can form iminium ion 4 [26]. The iminium ion 4 condenses with rhodanine anion 5 to form intermediate 6, which could be converted to 5 -arylidenerhodanines 3 after elimination of ammonia.

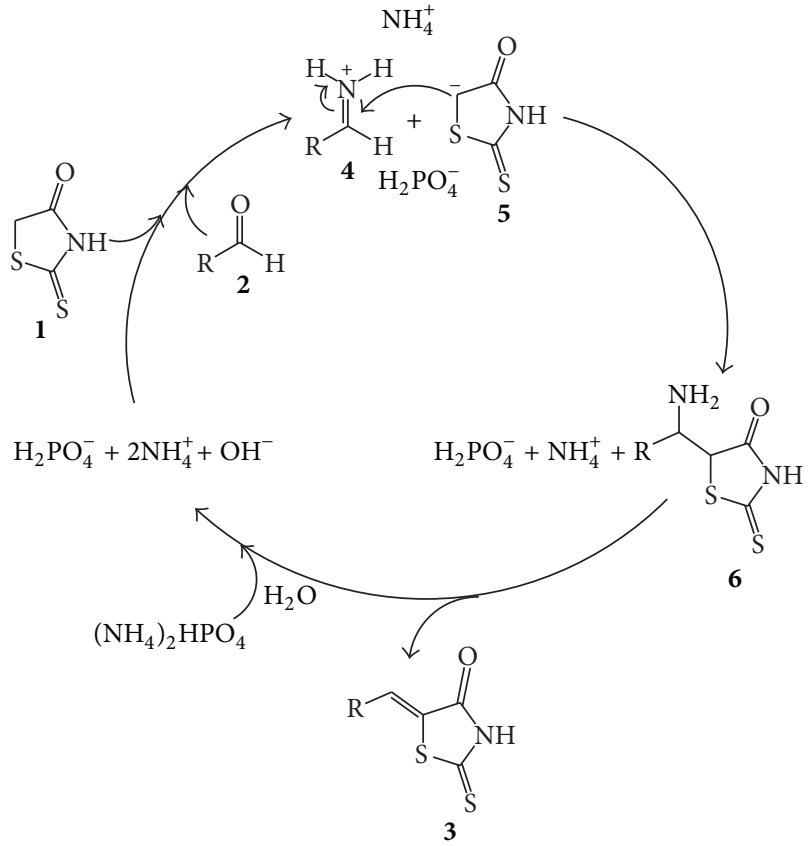

Scheme 2: Plausible mechanism for the synthesis of 5-arylidenerhodanines catalyzed by diammonium hydrogen phosphate.

\section{Conclusion}

In summary, a simple, efficient, and green procedure has been developed for the synthesis of 5 -arylidenerhodanines in water by the condensation of rhodanine with aldehydes in the presence of diammonium hydrogen phosphate. This method provides a simple and efficient protocol in terms of environmentally friendly, mild reaction conditions, short reaction times, high yields, and simple experimental and work-up procedures.

\section{Experimental}

4.1. Materials and Instrumentation. All chemicals were commercially available and were used as received. Melting points were determined on a X-4 micromelting point apparatus and are uncorrected. FT-IR spectra were obtained on a Nexus 470 spectrophotometer. ${ }^{1} \mathrm{H}$ NMR spectra were recorded on a Bruker Avance III 400 with TMS as internal standard.

4.2. General Procedure for the Preparation of 5-Arylidenerhodanines. A mixture of rhodanine ( $333 \mathrm{mg}, 2.5 \mathrm{mmol}$ ), the aldehyde $(2.5 \mathrm{mmol})$, and diammonium hydrogen phosphate (33 mg, $0.25 \mathrm{mmol})$ in $\mathrm{H}_{2} \mathrm{O}(3 \mathrm{~mL})$ was stirred at $90^{\circ} \mathrm{C}$. The progress of the reaction was monitored by thin-layer chromatography (ethyl acetate : petroleum ether $1: 1(\mathrm{v}: \mathrm{v})$ as eluent). After completion of the reaction, the solid material was filtered and washed with water. Further purification was carried out by crystallization from ethanol. Products obtained are all known compounds and were identified by comparing their physical and spectra data with the reported ones. 
TABLE 2: Diammonium hydrogen phosphate catalyzed synthesis of 5-arylidenerhodanines ${ }^{\mathrm{a}}$.

\begin{tabular}{|c|c|c|c|c|c|c|}
\hline Entry & $R$ & Time (min) & Product & Yield $(\%)^{\mathrm{b}}$ & $\mathrm{Mp}\left({ }^{\circ} \mathrm{C}\right)$ found & $\mathrm{Mp}\left({ }^{\circ} \mathrm{C}\right)$ reported \\
\hline 1 & $2,4-\mathrm{Cl}_{2} \mathrm{C}_{6} \mathrm{H}_{3}$ & 18 & $3 \mathbf{a}$ & 86 & $233-235$ & $233-234[12]$ \\
\hline 2 & $4-\mathrm{CH}_{3} \mathrm{C}_{6} \mathrm{H}_{4}$ & 14 & $3 b$ & 85 & $222-224$ & $221-223[12]$ \\
\hline 3 & $4-\mathrm{CH}_{3} \mathrm{OC}_{6} \mathrm{H}_{4}$ & 17 & $3 c$ & 88 & $248-250$ & $249-250[12]$ \\
\hline 4 & $2-\mathrm{ClC}_{6} \mathrm{H}_{4}$ & 10 & $3 d$ & 88 & $180-181$ & $181-182[12]$ \\
\hline 5 & $4-\mathrm{FC}_{6} \mathrm{H}_{4}$ & 9 & $3 e$ & 80 & $218-219$ & $219[1]$ \\
\hline 6 & $4-\mathrm{HOC}_{6} \mathrm{H}_{4}$ & 13 & $3 f$ & 83 & $308-310$ & $310[16]$ \\
\hline 7 & $4-\mathrm{BrC}_{6} \mathrm{H}_{4}$ & 15 & $3 g$ & 82 & $228-230$ & $230[1]$ \\
\hline 8 & $3-\mathrm{NO}_{2} \mathrm{C}_{6} \mathrm{H}_{4}$ & 16 & $3 \mathrm{~h}$ & 90 & $263-265$ & $263-265$ [12] \\
\hline 9 & $4-\mathrm{ClC}_{6} \mathrm{H}_{4}$ & 13 & $3 \mathbf{i}$ & 81 & $228-230$ & $229-230[12]$ \\
\hline 10 & $\mathrm{C}_{6} \mathrm{H}_{5}$ & 8 & $3 \mathbf{j}$ & 86 & $204-206$ & 205-207 [12] \\
\hline 11 & $2-\mathrm{HOC}_{6} \mathrm{H}_{4}$ & 16 & $3 \mathbf{k}$ & 84 & $222-223$ & $221-222[21]$ \\
\hline 12 & 2-Furyl & 4 & 31 & 85 & $227-229$ & $228-229[12]$ \\
\hline 13 & $4-\mathrm{HO}-3-\mathrm{CH}_{3} \mathrm{OC}_{6} \mathrm{H}_{3}$ & 11 & $3 \mathrm{~m}$ & 84 & $231-232$ & $231-231.5[21]$ \\
\hline
\end{tabular}

${ }^{a}$ Reaction condition: aldehyde $(2.5 \mathrm{mmol})$, rhodanine $(2.5 \mathrm{mmol}),\left(\mathrm{NH}_{4}\right)_{2} \mathrm{HPO}_{4}(0.25 \mathrm{mmol}), 90^{\circ} \mathrm{C}$, and water $(3 \mathrm{~mL})$.

${ }^{\mathrm{b}}$ Isolated yield.

\section{Acknowledgment}

This research work was financially supported by the Student Innovative and Venture Training Program of South Central University for Nationalities.

\section{References}

[1] M. Sortino, P. Delgado, S. Juárez et al., "Synthesis and antifungal activity of (Z)-5-arylidenerhodanines," Bioorganic \& Medicinal Chemistry, vol. 15, no. 1, pp. 484-494, 2007.

[2] Y. Momose, K. Meguro, H. Ikeda, C. Hatanaka, S. Oi, and T. Sohda, "Studies on antidiabetic agents. X. Synthesis and biological activities of pioglitazone and related compounds," Chemical and Pharmaceutical Bulletin, vol. 39, no. 6, pp. 1440$1445,1991$.

[3] J. H. Ahn, S. J. Kim, W. S. Park et al., "Synthesis and biological evaluation of rhodanine derivatives as PRL-3 inhibitors," Bioorganic and Medicinal Chemistry Letters, vol. 16, no. 11, pp. 29962999, 2006.

[4] O. Zvarec, S. W. Polyak, W. Tieu et al., "5-Benzylidenerhodanine and 5-benzylidene-2-4-thiazolidinedione based antibacterials," Bioorganic and Medicinal Chemistry Letters, vol. 22, no. 8, pp. 2720-2722, 2012.

[5] M. J. Robertson, G. Hadzic, J. Ambrus et al., "The rhodadyns, a new class of small molecule inhibitors of dynamin GTPase activity," ACS Medicinal Chemistry Letters, vol. 3, no. 5, pp. 352356, 2012.

[6] N. Zidar, T. Tomašić, R. Šink et al., "Discovery of novel 5-benzylidenerhodanine and 5-benzylidenethiazolidine-2, 4-dione inhibitors of MurD ligase," Journal of Medicinal Chemistry, vol. 53, no. 18, pp. 6584-6594, 2010.

[7] N. Zidar, T. Tomašić, R. Šink et al., "New 5-benzylidenethiazolidin-4-one inhibitors of bacterial MurD ligase: design, synthesis, crystal structures, and biological evaluation," European Journal of Medicinal Chemistry, vol. 46, no. 11, pp. 55125523, 2011.

[8] M. Song, C. Zheng, X. Deng et al., "Synthesis and bioactivity evaluation of rhodanine derivatives as potential anti-bacterial agents," European Journal of Medicinal Chemistry, vol. 54, pp. 403-412, 2012.

[9] S. Kamila, H. Ankati, and E. R. Biehl, "An efficient microwave assisted synthesis of novel class of Rhodanine derivatives as potential HIV-1 and JSP-1 inhibitors," Tetrahedron Letters, vol. 52, no. 34, pp. 4375-4377, 2011.

[10] S. Kamila, H. Ankati, E. Harry, and E. R. Biehl, "A facile synthesis of novel 3-(aryl/alkyl-2-ylmethyl)-2-thioxothiazolidin-4ones using microwave heating," Tetrahedron Letters, vol. 53, no. 17, pp. 2195-2198, 2012.

[11] V. Opletalova, J. Dolezel, K. Kralova, M. Pesko, J. Kunes, and J. Jampilek, "Synthesis and characterization of (Z)-5-arylmethylidenerhodanines with photosynthesis-inhibiting properties," Molecules, vol. 16, no. 6, pp. 5207-5227, 2011.

[12] X.-Z. Lian, Y.-Q. Li, and M.-Y. Zhou, "Ionic liquid/ $\mathrm{H}_{2} \mathrm{O}$ system promoted condensation of aromatic aldehydes and rhodanine," Chinese Journal of Organic Chemistry, vol. 26, no. 9, pp. 12721274, 2006.

[13] H. Li, J. Yang, S. Ma, and C. Qiao, "Structure-based design of rhodanine-based acylsulfonamide derivatives as antagonists of the anti-apoptotic Bcl-2 protein," Bioorganic \& Medicinal Chemistry, vol. 20, no. 14, pp. 4194-4200, 2012.

[14] J.-F. Zhou, Y.-Z. Song, F.-X. Zhu, and Y.-L. Zhu, "Facile synthesis of 5-benzylidene rhodamine derivatives under microwave irradiation," Synthetic Communications, vol. 36, no. 22, pp. 32973303, 2006.

[15] B.-Y. Yang and D.-H. Yang, "Solvent-free synthesis of 5benzylidene-2-thioxothiazolidin-4-ones and thiazolidine-2,4diones catalysed by glycine under microwave irradiation," Journal of Chemical Research, vol. 35, no. 4, pp. 238-239, 2011.

[16] N. H. Metwally, N. M. Rateb, and H. F. Zohdi, "A simple and green procedure for the synthesis of 5-arylidene-4-thiazolidinones by grinding," Green Chemistry Letters and Reviews, vol. 4, no. 3, pp. 225-228, 2011.

[17] D. Hardej, C. R. Ashby Jr., N. S. Khadtare, S. S. Kulkarni, S. Singh, and T. T. Talele, "The synthesis of phenylalanine-derived C5-substituted rhodanines and their activity against selected methicillin-resistant Staphylococcus aureus (MRSA) strains," European Journal of Medicinal Chemistry, vol. 45, no. 12, pp. 5827-5832, 2010. 
[18] K. Gong, Z.-W. He, Y. Xu, D. Fang, and Z.-L. Liu, "Green synthesis of 5-benzylidene rhodanine derivatives catalyzed by 1-butyl-3-methyl imidazolium hydroxide in water," Monatshefte für Chemie, vol. 139, no. 8, pp. 913-915, 2008.

[19] J.-J. Ma, S.-T. Gao, Z. Li et al., "Synthesis of 5-arylmethylidene2-thio-4-thiazolidinone derivatives catalyzed by alkaline ionic liquid," Chinese Journal of Organic Chemistry, vol. 28, no. 2, pp. 339-342, 2008.

[20] J. F. Zhou, F. X. Zhu, Y. Z. Song, and Y. L. Zhu, "Synthesis of 5-arylalkylidenerhodanines catalyzed by tetrabutylammonium bromine in water under microwave irradiation," ARKIVOC, vol. 2006, no. 14, pp. 175-180, 2006.

[21] M. Zhang, C. D. Wang, S. L. Yu, Z. B. Tian, and L. Zhang, "The condensation of rhodanine or N-phenylrhodanine with aromatic aldehyde under microwave, solid base as a supporter," Chemical Journal of Chinese Universities, vol. 15, no. 11, pp. 16471650, 1994.

[22] C.-J. Li and L. Chen, "Organic chemistry in water," Chemical Society Reviews, vol. 35, no. 1, pp. 68-82, 2006.

[23] A. Chanda and V. V. Fokin, "Organic synthesis "on water"', Chemical Reviews, vol. 109, no. 2, pp. 725-748, 2009.

[24] R. N. Butler and A. G. Coyne, "Water: nature's reaction enforcercomparative effects for organic synthesis "in-water" and "onwater"', Chemical Reviews, vol. 110, no. 10, pp. 6302-6337, 2010.

[25] S. Balalaie, M. Bararjanian, M. Sheikh-Ahmadi, S. Hekmat, and P. Salehi, "Diammonium hydrogen phosphate: an efficient and versatile catalyst for the one-pot synthesis of tetrahydrobenzo[b]pyran derivatives in aqueous media," Synthetic Communications, vol. 37, no. 7, pp. 1097-1108, 2007.

[26] S. Balalaie, S. Abdolmohammadi, H. R. Bijanzadeh, and A. M. Amani, "Diammonium hydrogen phosphate as a versatile and efficient catalyst for the one-pot synthesis of pyrano[2,3d]pyrimidinone derivatives in aqueous media," Molecular Diversity, vol. 12, no. 2, pp. 85-91, 2008.

[27] F. Darviche, S. Balalaie, F. Chadegani, and P. Salehi, "Diammonium hydrogen phosphate as a neutral and efficient catalyst for synthesis of 1,8-dioxo-octahydroxanthene derivatives in aqueous media," Synthetic Communications, vol. 37, no. 7, pp. 1059-1066, 2007.

[28] M. Dabiri, P. Salehi, M. Baghbanzadeh, Y. Vakilzadeh, and S. Kiani, "Diammonium hydrogen phosphate as an efficient and inexpensive catalyst for the synthesis of bis(indolyl)methanes under solvent-free conditions," Monatshefte fur Chemie, vol. 138, no. 6, pp. 595-597, 2007.

[29] H. Huo, Z. Zhou, A. Zhang, and L. Wu, "Ruthenium(II)catalyzed transfer hydrogenation of aldehydes with new watersoluble monotosylated ethylenediamines as ligands," Research on Chemical Intermediates, vol. 38, no. 1, pp. 261-268, 2012.

[30] Z. Zhou and Q. Ma, "Polyethylene glycol-bound Ru catalyst for asymmetric transfer hydrogenation of aromatic ketones in water," Applied Organometallic Chemistry, 2011.

[31] Z. Zhou and Y. Sun, "Water-soluble chiral aminosulfonamides as ligands for ruthenium(II)-catalyzed asymmetric transfer hydrogenation," Catalysis Communications, vol. 10, no. 13, pp. 1685-1688, 2009.

[32] Z. Zhou and L. Wu, "Proline-based amino amide hydrochlorides as ligands for asymmetric transfer hydrogenation of prochiral ketones in water," Catalysis Communications, vol. 9, no. 15, pp. 2539-2542, 2008. 

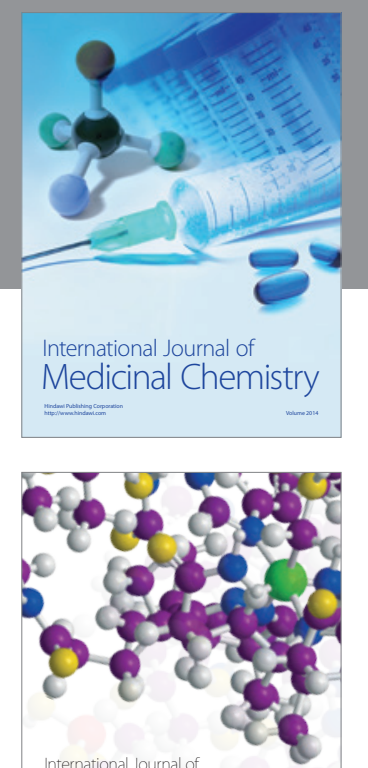

\section{Carbohydrate} Chemistry

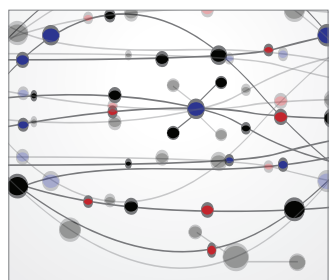

The Scientific World Journal
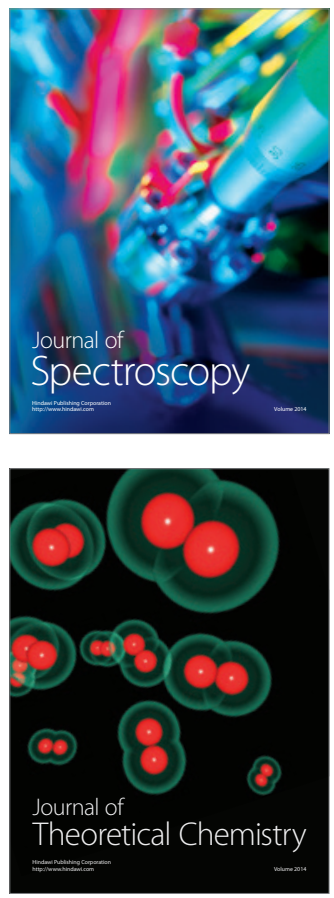
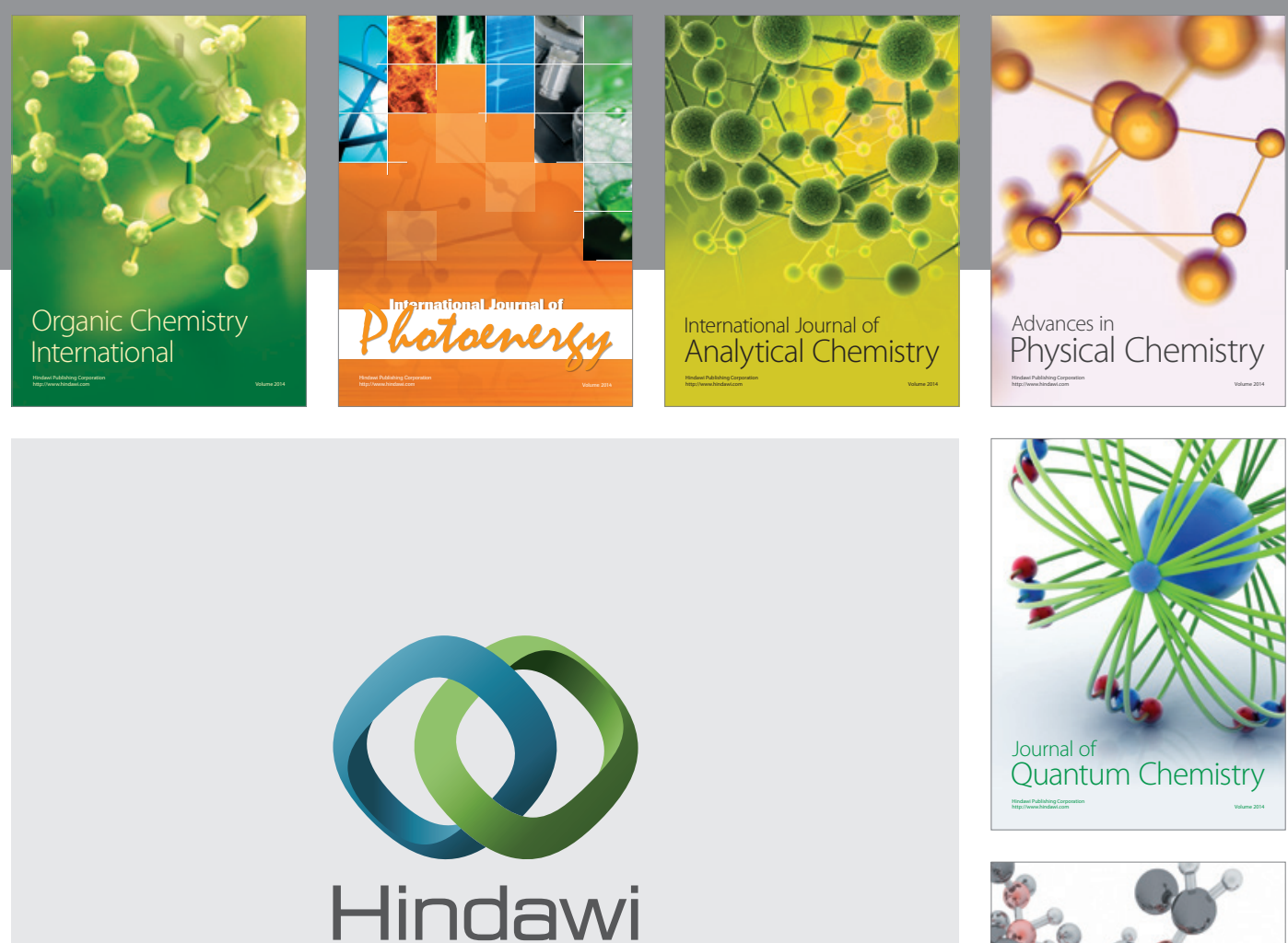

Submit your manuscripts at

http://www.hindawi.com

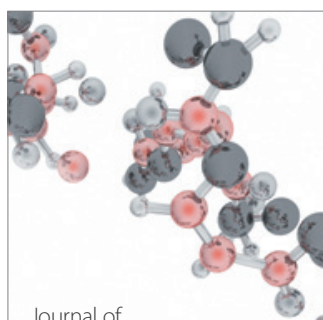

Analytical Methods

in Chemistry

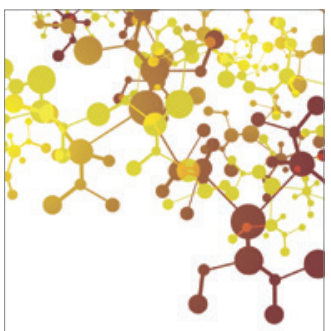

Journal of

Applied Chemistry

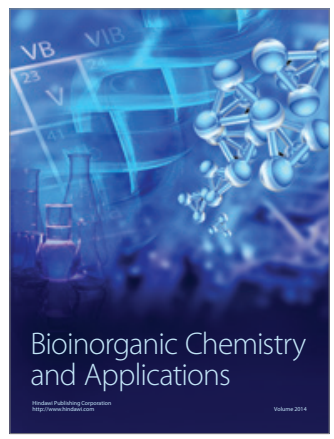

Inorganic Chemistry
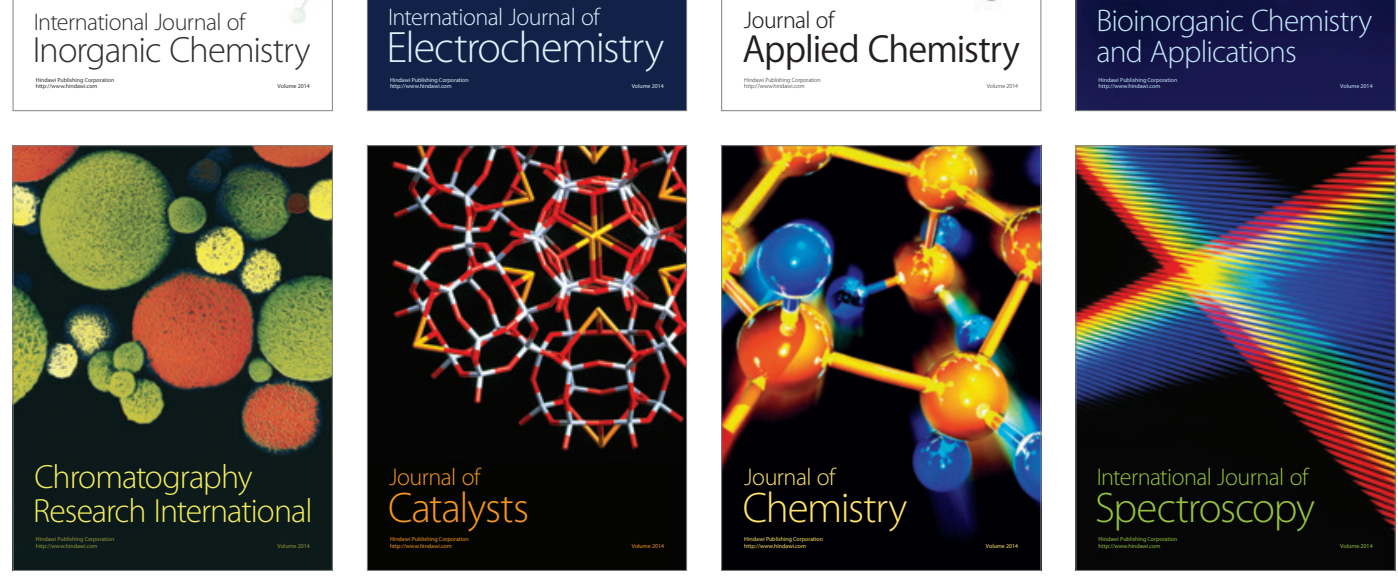